\title{
Investigation of Parasitic Infections among Primates in Selected Zoological Gardens in Nigeria
}

\author{
Joseph Johnson $^{1} \&$ Audu Danladi Naomi ${ }^{2 *}$ \\ 1,2Department of Zoology, Adamawa State University, Mubi, Nigeria. Email: naomidanladi778@yahoo.com² ${ }^{2 *}$ \\ DOI: http://doi.org/10.38177/ajast.2022.6110
}

Copyright: () 2022 Joseph Johnson \& Audu Danladi Naomi. This is an open access article distributed under the terms of the Creative Commons Attribution License, which permits unrestricted use, distribution, and reproduction in any medium, provided the original author and source are credited.

\section{ABSTRACT}

In nature, wild animals live on large area and have consequently, a low genetic resistance against parasitic infections because of hoe exposure. When herds of these wild animals are kept in captivity in Zoological Gardens, the problem of parasite infection can aggravate and pose a serious threat to endangered species, occasionally causing sudden and unexpected local declines in abundance; unfortunately, there have been few detailed and comprehensive studies on the common parasitic infections, prevalence of the parasitic infections in the primates and the Health care management of the captive primates. The focus of the research work is on investigation of parasitic infection among primates in selected Zoological Gardens in Nigeria the researcher has the following objectives, The researcher adopted experimental method sample of fresh feaces were collected differently for 5 days and was examined at two different laboratory, that Ibadan and Jos. The Ibadan Zoological Garden twenty seven species of primates were examined, with only six infested with Trichuris Trichuria parasite; common in chimpanzee, mona monkey, Tantalus and white throated. In Jos Plateau Zoological Garden, twenty-four species of primates were examined only thirteen primates were infested with Trichuris Trichuria, F buskii, Eimeria, Ascaris Lumbricoides, S. mansoni, Hetrophyes, Those infested, are Red patas, softy mongabey, Baboon, Mona Monkey, Tantalus, and Chimpanzee. Kano Zoological Garden, thirty species of primates were examined, only eleven were infested with Ascaris Lumbricoides, Eimeria, Trichuris Trichuria, Fasciola those infested are Baboon, Chimpanzee, Mona Monkey, Patas, Tantalus Monkeys. All the above examination of the faecal sample material, a direct wet smear was used to reveal the parasites; examined with a how power objective (10x).

Keywords: Zoology, Parasitology, Primates, Infection.

\subsection{Introduction}

In nature, wild animals live on large areas and have consequently a low genetic resistance against parasitic infections because of low exposure. When herds of these wild animals are kept in captivity in zoological gardens, the problem of parasitic infections can aggravate and pose a serious threat to endangered species, occasionally causing sudden and unexpected local declines in abundance. Knowledge of their diseases need to be gained, especially when bred for re-introduction in the wild.

Unfortunately, there have been few detailed and comprehensive studies on the prevalence of the intestinal parasites in animals housed in zoological garden. Non-human primates (NHP) are one of most common groups of animals in zoological gardens for their role in public entertainment (Dawet et al., 2013). They are however known to harbour different gastro-intestinal parasite species which affect their survival and reproductive activity by causing gastro enteritis, haemorrhage, extra-intestinal infection, spontaneous abortion and death (Colin et al., 2005). NHP are particularly vulnerable to parasitic infestations because many species live in cohesive groups characterized by frequent social interactions that facilitate parasite transmission between individuals (Stoner, 1996).

Infestations by gastro-intestinal parasites have been reported in a range of NHP hosts which include gorilla (Gorilla gorilla), chimpanzee (Pan troglodytes), green monkey (Chlorocebus sabaeus), red patas (Erythrocebus patas) (Adedokun et al., 2002), mandril monkeys (Papio leucophaeus) (Akpan et al., 2010) white collared mangabey (Cercocebus torquatus), mona monkey (Cercopithecus mona) and anubis baboon (Papio anubis) (Mbaya et al., 2009 Dawet et al., 2013). Parasitic diseases often represent a major concern in zoo animals for the high 
environmental contamination due to the maintenance of animals in confined areas (Gracenea, et. al, 2002). In wild conditions, animals have some natural resistance against parasitic diseases and there is a state of equilibrium between the parasite and the host and it seldom led to harmful infection unless stressed. In captivity wild animals may succumb to parasitic infections due to environmental stress such as change in the living conditions and space limitations (Rana, 2015). The constant stress of captivity makes animals more susceptible to parasitic infection as the immune system of these captive animals becomes weak (Cordon et al., 2008). Studies on parasitic diseases of wildlife are still in infancy in Nigeria with only few systematic studies having been undertaken, and data are still on the base line.

Zoo animals often come in contact with humans from the zoo keepers and game rangers tending them to park visitors and people who keep them as pets. NHP are susceptible to many biological agents that infect human beings. However, Balantidium and Enterobius, and Giardia infections in the gorillas and chimpanzees respectively at the Agodi and University of Ibadan (UI) zoos were thought to be of human origin because the same animals had never escaped from captivity. This thought was confirmed in another study by Akinboye et al. (2010) who reported the presence of both helminths (Ascaris lumbricoides, hookworms and Trichuris trichiura) and protozoa (Entamoeba histolytica and Giardia lamblia) among zoological garden workers while only helminths (Strongyloides spp, Trichuris spp and Ascaris spp) were found in zoo animals and birds in the UI zoological garden. In a study carried out on primate bush meat and pets in Cameroon, seven nematode species, three protozoan species, one trematode species and one cestode species were reported (Pourrut et. al. 2011) Eight different parasites were found in Cercopithecus nictitans and six in C. neglectus, C. pogonias and Cercocebus agilis. Heminths were found in $77 \%$ monkeys, and protozoa in 36\%. Among the helminthes species, Strongyloides fuelleborni was more prevalent in bush meat monkeys than in pets (55\% versus $15 \%)$.

Parasitic diseases constitute one of the major problem causing mortality in wild animals while in captivity, the effects of which range from sub-clinical to death. Parasites cause a multitude of problems for wildlife and even spread to human, although it often appears that wildlife have adapted to the presence of parasites, they have not adapted to the adverse effects of parasitism. Inadequate information on diseases and parasites of zoo animals is a major limiting factor in zoological gardens especially in Nigeria. The aim of this research work is to investigate parasitic infections among primates of selected zoological gardens in Nigeria with the subsequent objectives.

\subsection{Methods}

Fresh faecal samples from all the captive primates species was collected at selected zoological gardens in northern Nigeria (Kano, Jos) Southern Nigeria (Ibadan). Approximately $10 \mathrm{~g}$ of faces was collected in the morning at about $8.00 \mathrm{am}$ before the cages were cleaned by the zoo keepers. Each animal was sample once during the study and if they lived in groups (e.g. monkeys, deer) one sample from the group were taken.

The samples was collected into small plastic seal bags. During a visit about 10 samples was collected at random whenever a fresh sample of a particular animals was available and the sampling was done in every day until a final target of all the mammal species in Zoological garden was reached. Samples was brought to the laboratory in a cooler and was stored at $4^{\circ} \mathrm{C}$ until the analysis. Processing of the samples was completed within a week in the 
parasitology laboratory, in the Department of Biological science of the university of the states the sample was collected (Ibadan) Kano and (Jos) using a modified salt floatation method, Sheather's sucrose floatation method, direct saline and iodine mounts.

\subsection{Examination of Samples}

Samples obtained was examined using the methods as described further.

\subsection{Direct Wet Smear}

Examination of the faecal material as a direct smear may or may not reveal organisms; in light infections, the number of organisms present may be very low. The direct wet smear was prepared by mixing a small amount of stool (about $2 \mathrm{mg}$ ) with a drop of $0.85 \% \mathrm{NaCl}$; this mixture were provide a uniform suspension under a 22- by 22-mm coverslip. A 2-mg sample of stool forms a low cone on the end of a wooden applicator stick. If a fresh stool specimen is received and if blood and mucus are present, the specimen was examined as a direct mount making sure to sample the bloody areas. The entire 22 - by $22-\mathrm{mm}$ coverslip was systematically examined with the low power objective $(10 \mathrm{x})$ and low light intensity; any suspicious objects was examined with the high dry objective $(40 \mathrm{x})$. Use of an oil immersion objective $(100 \mathrm{x})$ on wet mounts is not routinely recommended. Many workers think that the use of the oil immersion objective on this type of preparation is impractical, especially since morphological detail is more readily seen by oil immersion examination of the permanent stained smear. This is particularly true in a busy clinical laboratory situation.

\subsection{Results}

At total of eighty one captive primates were examined from three selected Zoological Gardens, Ibadan, Jos and Kano. Ninety questionnaire were distributed in three selected Zoological Gardens, and a total of Eighty seven respondents to the questionnaire. Common and prevalence of parasitic infections among different pieces of captive primates in three zoological Gardens in Nigeria.

Table 1. Common Parasitic Infections among Non- Human primates in Three Zoological Gardens in Nigeria

\begin{tabular}{|c|c|c|c|c|}
\hline S/N & $\begin{array}{c}\text { Species of Primates } \\
\text { University of Ibadan Zoological } \\
\text { Garden }\end{array}$ & No. Examined & Parasites found & No. Infested \\
\hline $\mathbf{1}$ & Baboon & 3 & 2 Trichuris Trichuria & 2 \\
\hline $\mathbf{2}$ & Chimpanzee & 3 & None & 0 \\
\hline $\mathbf{3}$ & Drill Monkey & 2 & 1 Trichuris Trichuria & 1 \\
\hline $\mathbf{4}$ & Mona Monkey & 5 & None & 0 \\
\hline $\mathbf{5}$ & Softy Mongabey & 4 & None & 0 \\
\hline $\mathbf{6}$ & Patas & & \\
\hline
\end{tabular}


Asian Journal of Applied Science and Technology (AJAST)

Volume 6, Issue 1, Pages 82-88, January-March 2022

\begin{tabular}{|c|c|c|c|c|}
\hline $\mathbf{7}$ & Tantalus & 5 & 1 Trichuris Trichuria & 1 \\
\hline $\mathbf{8}$ & White Throated & 3 & 2 Trichuris Trichuria & 2 \\
\hline & Sub -Total & $\mathbf{2 7}$ & & \\
\hline
\end{tabular}

Source: Field Work (July, 2021)

Result from the zoological garden of University of Ibadan shows that out of 27 primates examined, only 6 were infested with same parasite, Trichuris spp, which represents $22.2 \%$ of the primates examined. Those infested are chimpanzee, Mona Monkey, Trantalus Monkey and white throated. None of the Baboon, softy Mongabey and Patas was infested.

Table 2. Species of Primates Jos Plateau Zoological Garden

\begin{tabular}{|c|c|c|c|c|}
\hline $\mathbf{S} / \mathbf{N}$ & $\begin{array}{c}\text { Species of Primates } \\
\text { Jos Plateau Zoological Garden }\end{array}$ & No. Examined & Parasites found & No. Infested \\
\hline 1 & Red Patas & 6 & $\begin{array}{c}1 \text { Trichuris Trichuria } \\
1 \text { Fibusfii }\end{array}$ & 1 \\
\hline 2 & Softy Mongabey & 3 & $\begin{array}{c}2 \text { Eimeria } \\
2 \text { Ascaris Lumbricoides } \\
1 \text { Fasciola } \\
2 \text { Trichuris }\end{array}$ & 2 \\
\hline 3 & Baboo & 6 & $\begin{array}{c}1 \text { S. Mansain } \\
1 \text { Ascaris Trichuria } \\
1 \text { Eimeria }\end{array}$ & 4 \\
\hline 4 & Mona Monkey & 3 & $\begin{array}{c}1 \text { Hetrophyes } \\
2 \text { Trichuris Trichuria } \\
1 \text { Eimeria }\end{array}$ & 3 \\
\hline 5 & Tantalus & 3 & 1 Heverophyes SPP & 1 \\
\hline 6 & Chimpanzee & 3 & $\begin{array}{c}1 \text { S. Mansoni, } \\
1 \text { F. buskii } \\
1 \text { Trichuris Trichuria } \\
1 \text { Eimeria }\end{array}$ & 2 \\
\hline & Sub-Total & 24 & & \\
\hline
\end{tabular}

Source: Field work (September, 2021) 
While result from the Jos Plateau Zoological Garden shows that out of 24 captive primates examined, 13 were infested with different species of the parasites which include: Trichuris, Trichuria F.buskii, Eimeria, Ascaris Lumricoides S. Mansoni, Hetrophyes, which represents 54.2\% of the primates examined. Those infested are Red Patas, Softy Mongabey, Baboo, Mona Monkey, Tantalus monkey, and Chimpanzee. All the primates species are exposed to one or two parasites.

Table 3. Species of Primates Kano Zoological Garden

\begin{tabular}{|c|c|c|c|c|}
\hline $\mathbf{S} / \mathbf{N}$ & $\begin{array}{c}\text { Species of Primates } \\
\text { Kano Zoological Garden }\end{array}$ & No. Examined & Parasites found & No. Infested \\
\hline $\mathbf{1}$ & Baboon & 6 & $1 \quad$ Ascaris Lumbricoides & 2 \\
\hline $\mathbf{2}$ & Chimpanzee & 6 & $2 \quad$ Eimeria SPP & 2 \\
\hline $\mathbf{3}$ & Mona Monkey & 6 & 1 Ascaris Lumbricoides & 3 \\
\hline $\mathbf{4}$ & Patas & 6 & $2 \quad$ Eimeria SPP & 2 \\
\hline $\mathbf{5}$ & Tantalus & 6 & $1 \quad$ Trichuris Trichuria & \\
\hline & Sub-Total & $\mathbf{3 0}$ & $1 \quad$ Fasciola SPP & 2 \\
\hline
\end{tabular}

Source: Field work (August, 2021)

Similarly Kano Zoological Garden, All the primates examined are infested with one or two parasites, the result shows 30 captive primates were examined, out of which 11 were infested with different species, which include: Ascaris, Eimeria, Trichuris and Fasciola spp. Which represents $36.7 \%$ of the examined primates. From the total result, it shows that the common parasitic infections among different species of captive primates in the three zoological Gardens in Nigeria are: - Trichuris, Trichiuris, F. buskii ssp, Eimeria spp, Ascaris Lumbricoides, S. mansoni and Hetrophyes spp. The above report, confirmed with the study by Akinboye et al., (2010) who reported the presence of both helminthes "(Ascaris lumbricoictes, hookworms and Trichuris trichiura)".

Prevalence of parasitic infections among different species of captive primates in three Zoological Gardens in Nigeria

Based on table 1. The prevalence of parasitic infections among different species of captive primates in Ibadan Zoological Gardens is Trichuris trichiura with $22.3 \%$ among 27 primates examined. Garden has the following:

1. Trichuris Trichiura - (6) $28.6 \%$

2. F. buskii - (3) $14.3 \%$ 

3. Mimeria spp
- (5) $23.8 \%$
4. Ascaris Lumbricoides
(3) $14.3 \%$
5. S. Manasoni
- (2) $9.5 \%$
6. Hetrophyes SPP -
(2) $9.5 \%$

The result shows that prevalence of Trichuris trichiura 28.6\%, Eimeria 23.8\%, F.buskii and Ascaris Lumbricoides $14.3 \%$ each among the primates examined.

While Kano zoological Garden shows the following parasitic infections: -

1. Ascaris Lumbricoides - (2) $16.7 \%$

2. Eimeria - (7) $58.3 \%$

3. Trichuris Trichuria - (2) $16.7 \%$

4. Fasciola spp - (1)8.3\%

The result shows prevalence of Eimeria 58.3\%, Ascaris Lumbricoides and Trichuris Trichuria 16.7\% each and Fasciola spp $8.3 \%$.

The result of the finding, has similar opinion with (Nunn et al., 2003; Ezenwa, 2004; Ezenwa et al., 2006; Nunn and Dokey, 2006), which stated that "parasite species richness, the number of parasite species infecting a population should be higher in species with small home ranges, large group sizes, high population densities, greater social contact and greater dietary diversity".

\subsection{Conclusion}

Collections of wild animals have been in existence since antiquity. The history of modern Zoos, Started 200 years ago with the creation of the first public Zoos. The modern Zoo that emerged in the early $19^{\text {th }}$ Century at Halifax, London, Paris and Dulin, was focused on providing educational exhibits to the public for entertainment, as well as the requirements of scholarly research, inspiration and conservations of primate species.

The result shows the Zoos have the carrying capacity of the primates and are housed base on species, the captive primates are adequately feed, there are clinic in each of the Zoo, with adequate staff. Primates are constantly dewormed against parasitic infections, each zoo has allocations of funds for health care of the primates and staff(s).

The common parasitic infections in the selected zoological garden are: - Trichuris Trichuria, F. buskii, Emeria, Ascaris Lumbricoides, Hetrophyes, S. Mansoni, The parasitic infections, infest primates as followings: Chimpanzee, mona Monkey, Tantalus monkey, white throated, Red patas, softy mongabey, Babppn, these shows that the species of the primates have how resistance to the infections and need adequate Health care.

\section{Declarations}

Source of Funding

This research did not receive any grant from funding agencies in the public, commercial, or not-for-profit sectors. 


\section{Competing Interests Statement}

The authors declare no competing financial, professional and personal interests.

\section{Consent for publication}

Authors declare that they consented for the publication of this research work.

\section{Reference}

Dawet A., Yakubu D. P. \& Butu H. M., (2013). Survey of gastrointestinal parasites of non-human primates in Jos zoological Garden. Journal of Primatology, 2(1): 1-3.

Colin A.C., Thomas G.R. \& Tony L.G., (2005). Primates and the ecology of their infectious diseases: How will anthropogenic change affect host-parasite interactions? Evolutionary Anthropology, 14(4): 134-144.

Stoner K.E., (1996). Prevalence and intensity of intestinal parasites in mantled howling monkeys (Alouatta palliata) in North-eastern Costa Rica: Implications for conservation biology. Conservation Biology, 10(2): 539-546.

Adedokun, O. A, Adedokun R. A. M., Emikpe B.O, Ohore, O.G, Oluwayelu, D.O \& Ajayi O.L., (2002). Concurrent fatal helminthosis and balantidosis in red monkey (Erythrocebus patas) in Ibadan, Nigeria. Nigerian Veterinary Journal, 23(2): 56-59.

Akpan P. A, Abraham J. T \& Ekwetiong P.O., (2010). Survey of gastro-intestinal parasites of chimpanzees and drill monkeys in Drill Ranch, Calabar, Cross River State, Nigeria. African Research Review, 4(3a): 334-340.

Mbaya A.W., Aliyu M.M., Ibrahim U.I., Joshua L. \& Joel C., (2009). Gastrointestinal parasites and associated parasitic load among free-living primates in Gashaka-Gunti National Park, Nigeria. Nigerian Veterinary Journal, 30(4): 33-39.

Gracenea M, Gomez M.S, Torres J, Carne E, Fernadez-Moran J. (2002) Transmission dynamics of Cryptosporidium in primates and herbivores at the Barcelona Zoo:A long-term study. Vetenary Parasitology 2002, 104: 19-26.

Rana M.A, Jabeen F, Shabnam M, Ahmad I, Hassan M.M. (2015) Comparative study of endo-parasites in captive hog deer (Axis porcinus) International Journal of Bioscience. 6(1): 162-170.

Cordon G.P, Prados A.H, Romero D, Moreno S.M, Pontes A, Osuna A, Rosales M.J. Intestinal parasitism in the animals of the zoological garden "Pena Escrita"(Almunecar, Spain) Vet. Parasitol. 2008, 156: 302-309.

Akinboye D.O, Ogunfetimi A. A, Fawole O, Agbolade O., Ayinde O.O., et.al (2010) Control of parasitic infections among workers and inmates in a Nigerian zoo. Nigerian Journal of Parasitology, 31: 35-38.

Pourrut X., Diffo J.L., Somo R.M., Bilong Bilong C.F., Delaporte E, et al. (2011) Prevalence of gastrointestinal parasites in primate bushmeat and pets in Cameroon. Vet Parasitol., 175: 187-191. 